\title{
THE MORPHOLOGY OF PACHYTENE CHROMOSOMES OF SOME EU.SORGHUMS')
}

\author{
M. L. MAGOON, M. A. TAYYAB ${ }^{2)}$ AND R. S. SADASIVAIAH \\ Central Tuber Crops Research Institute, Trivandrum-10, Kerala, India
}

Received October 5, 1966

Pachytene analysis in species and species hybrids have proved to be an important tool in recent cytotaxonomic investigations in several taxa. It may, however, be seen that success in pachytene analysis has been reported largely in plant material with low haploid chromosome number and in general with small sized chromosomes and not vice versa, due to the difficulty in getting well spread preparations for critical analysis of the entire complement. In instances where non-homologous pairing occurs, a great difficulty has also been experienced in spreading the chromosomes. It has been observed that certain inbred lines of maize give well spread preparations while others give poor spreading. This suggests the role of genetic factors influencing this differential behaviour of chromosomes of the inbred lines (Randolph, 1948, Wellwood and Randolph, 1957 and Rees, 1961). The location of centromere in the instances where it is not sharply identifiable also offers considerable difficulties in analyzing the arm ratio and also poor preparations have been obtained where the ratio of chromosomal and nuclear volume is high. However, it will be seen from the photomicrographs presented in the present investigation that Sorghum appears to be suitable material for pachytene analysis. Centromeres are sharply definable and in none of these Eu-Sorghums, nonhomologous pairing or stickiness was noticed. It is, therefore, the purpose of this paper to present data on the karyomorphology of six Eu-Sorghums that would be useful in building up an "inclusive herbaria" of Sorghums (see Magoon et al. 1964) with the ultimate objective of tracing the interrelationships amongst them.

\section{MATERIAL AND METHODS}

The following material of Sorghum were used in the present investigation.

1. S. margaritiferum Stapf.

1) These studies were largely undertaken at the Division of Botany, I. A. R. I., New Delhi where the authors were previously located. They are, therefore, grateful to the Director, I. A. R.I., Dean of P.G. School and Head of the Division of Botany for their keen interest and facilities. One of us (R.S.S.) is grateful to C.S.I.R. for the award of a Senior Research fellowship during the course of the study. One of us (M.A.T.) is also thankful to the Director of Agriculture (Department of Agriculture), Government of Maharashtra for encouragement during the course of this investigation. Cooperation of C.T.C.R.I., Trivandrum and Rockefeller Foundation, I. A.R.I. is also hereby acknowledged.

2) Present address: College of Agriculture, Nagpur, Maharashtra State, India. 
2. S. aethiopicum (Hack.) Rupr. ex Stapf.

3. Ramkel (S. cernuum Host. var. orbiculatum Snowden)

4. Saoner (S. cernuum Host. var orbiculatum Snowden)

5. Sheosagar (S. durra stapf. var. mediocre Snowden)

6. Janera Joshia (S. Roxburghii stapf. var. nanum Snowden)

Seeds of the various species and varieties of Sorghum were obtained through the courtesy of the Rockefeller Foundation, Division of Botany, I.A.R.I., New Delhi. For the study of chromosome morphology and microsporogenesis, the simple propiono-carmine smear method (Swaminathan, Magoon and Mehra, 1954) was followed. Since in the Sorghum material under study, the pachytene chromosomes were found to be somewhat comparable to tomato (Barton, 1950), straight line drawings of the different regions were made from photomicrograph and such drawings were further used for measruing the length etc. For the sake of convenience in comparing the chromosome sizes "Relative length" was used which represents the ratio in percentage of the length of the individual chromosome to that of the longest in the complement (Huziwara, 1956).

\section{OBSERVATIONS}

\section{Morphology of pachytene chromosomes:}

With regard to the nature of chromosome pairing, it was observed that synapsis of homologous chromosomes at mid-pachytene stage was found to be complete and apparently normal in all the six Eu-Sorghums (Figs. 1 to 12). The pycnotic regions on both the arms were well differentiated and further the centromere of each of the pachytene bivalents could be easily distinguished with great accuracy as an oval shaped achromatic structure. Based on the average values of lengths obtained by accurate measurements of the bivalents in several of the completely analyzable nuclei (a minimum of ten), the ten pachytene bivalents of each of the Eu-Sorghums have been arranged and numbered in order of their decreasing length as chromosome I to chromosome X (chromosome I being the longest and chromosome $\mathrm{X}$ as the shortest in the complement). Idiograms showing details of the pachytene chromosomes are also presented (see Figs. 1 to 12). The data on total length, relative length and arm ratio obtained for all the chromosomes are given in Table 1. Additional diagnostic features of the ten pachytene bivalents in each taxa are described briefly as follows:

Chromosome I: This is the longest of the complement having a nucleolar organizing region in the short arm lying very close to the centromere. The pycnotic regions on both the arms are almost of equal length in $S$. margaritiferum, S. aethiopicum and Ramkel. However, in Sheosagar and Janera Joshia, the pycnotic region on the long arm is slightly longer than that on the short arm, while the converse is true in Saoner. Further, the pycnotic regions on both the arms end abruptly in Ramkel and Saoner. In Janera Joshia the nucleolar organizing region in the short arm lying very close to 


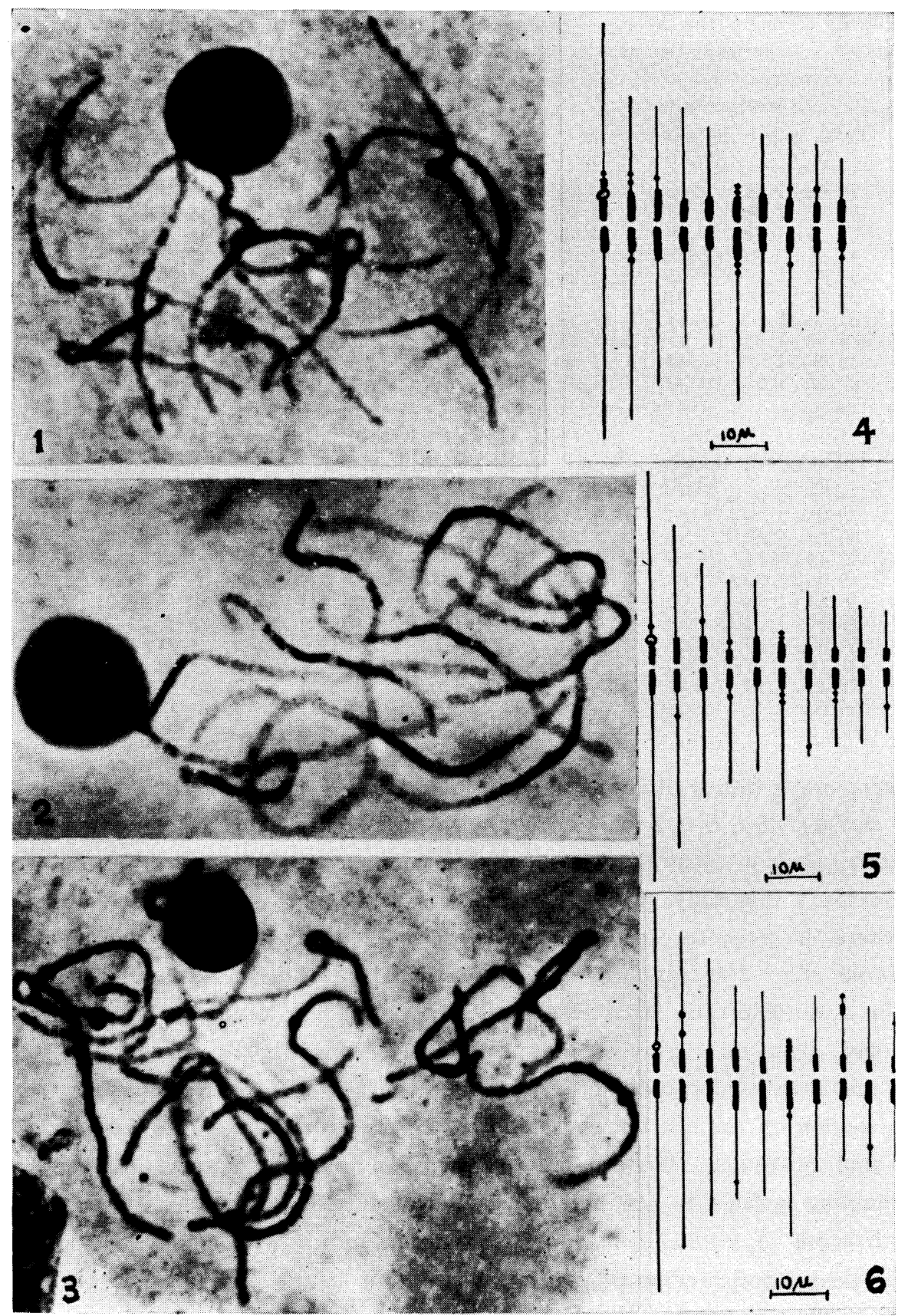

Figs. 1 to 3. Ten pachytene bivalents of S. margaritiferum ; S. aethiopicum and Ramkel respectively (X $1200 ; 1250$ and 1250 respectively).

Figs. 4 to 6 . The idiogram of the pachytene chromosomes of A-S. margaritiferum; B-S. aethiopicum and C-Ramkel. 
Table 1. Showing the average measurements of total length, relative length and arm ratio of the pachytene chromosomes in the six Eu-Sorghums

\begin{tabular}{|c|c|c|c|c|c|c|c|c|c|}
\hline \multirow{2}{*}{$\begin{array}{l}\text { Chromo- } \\
\text { some } \\
\text { No. }\end{array}$} & \multicolumn{3}{|c|}{ S. margaritiferum } & \multicolumn{3}{|c|}{ S. aethiopicum } & \multicolumn{3}{|c|}{ Ramkel } \\
\hline & $\begin{array}{l}\text { Total length } \\
\text { in } \mu\end{array}$ & \begin{tabular}{|c} 
Relative \\
length
\end{tabular} & $\begin{array}{l}\text { Arm } \\
\text { ratio }\end{array}$ & $\begin{array}{l}\text { Total length } \\
\text { in } \mu\end{array}$ & $\left|\begin{array}{c}\text { Relative } \\
\text { length }\end{array}\right|$ & $\begin{array}{l}\text { Arm } \\
\text { ratio }\end{array}$ & $\begin{array}{l}\text { Total length } \\
\text { in } \mu\end{array}$ & \begin{tabular}{|c} 
Relative \\
length
\end{tabular} & $\begin{array}{l}\text { Arm } \\
\text { ratio }\end{array}$ \\
\hline $\begin{array}{r}\text { I } \\
\text { II } \\
\text { III } \\
\text { IV } \\
\text { V } \\
\text { VI } \\
\text { VII } \\
\text { VIII } \\
\text { IX } \\
\text { X }\end{array}$ & $\begin{array}{l}76.69 \pm 1.55 \\
59.72 \pm 1.39 \\
52.07 \pm 1.29 \\
43.96 \pm 0.89 \\
40.55 \pm 1.17 \\
39.86 \pm 0.66 \\
37.18 \pm 1.23 \\
35.99 \pm 1.38 \\
32.36 \pm 1.53 \\
27.57 \pm 1.92\end{array}$ & $\begin{array}{r}100 \\
78 \\
68 \\
57 \\
53 \\
52 \\
48 \\
47 \\
42 \\
36\end{array}$ & $\begin{array}{l}1: 1.10 \\
1: 1.49 \\
1: 1.40 \\
1: 1.00 \\
1: 1.24 \\
1: 4.89 \\
1: 1.16 \\
1: 1.15 \\
1: 1.16 \\
1: 1.30\end{array}$ & $\begin{array}{l}75.50 \pm 1.63 \\
59.50 \pm 1.42 \\
43.64 \pm 2.04 \\
38.08 \pm 1.37 \\
35.94 \pm 1.69 \\
35.44 \pm 1.58 \\
31.55 \pm 1.59 \\
27.89 \pm 1.07 \\
25.89 \pm 1.07 \\
22.61 \pm 1.06\end{array}$ & $\begin{array}{r}100 \\
79 \\
62 \\
50 \\
48 \\
47 \\
42 \\
37 \\
34 \\
30\end{array}$ & $\begin{array}{ll}1: 1.12 \\
1: 1.30 \\
1: 1.28 \\
1: 1.33 \\
1: 1.30 \\
1: 4.51 \\
1: 1.23 \\
1: 1.23 \\
1: 1.29 \\
1: 1.28\end{array}$ & $\begin{array}{l}73.81 \pm 1.83 \\
58.65 \pm 2.08 \\
48.22 \pm 1.16 \\
40.29 \pm 1.14 \\
36.79 \pm 1.88 \\
36.20 \pm 2.06 \\
33.11 \pm 2.18 \\
31.69 \pm 1.65 \\
29.42 \pm 2.13 \\
27.83 \pm 1.13\end{array}$ & $\begin{array}{r}100 \\
83 \\
68 \\
57 \\
52 \\
51 \\
47 \\
45 \\
42 \\
39\end{array}$ & $\begin{array}{l}1: 1.20 \\
1: 1.17 \\
1: 1.20 \\
1: 1.31 \\
1: 1.37 \\
1: 4.57 \\
1: 1.16 \\
1: 1.07 \\
1: 1.36 \\
1: 1.27\end{array}$ \\
\hline \multirow{2}{*}{$\begin{array}{l}\text { Chromo- } \\
\text { some } \\
\text { No. }\end{array}$} & \multicolumn{3}{|c|}{ Saoner } & \multicolumn{3}{|c|}{ Sheosagar } & \multicolumn{3}{|c|}{ Janera Joshia } \\
\hline & $\begin{array}{l}\text { Total length } \\
\text { in } \mu\end{array}$ & $\begin{array}{l}\text { Relative } \\
\text { length }\end{array}$ & $\begin{array}{l}\text { Arm } \\
\text { ratio }\end{array}$ & $\begin{array}{l}\text { Total length } \\
\text { in } \mu\end{array}$ & $\begin{array}{l}\text { Relative } \\
\text { length }\end{array}$ & $\begin{array}{l}\text { Arm } \\
\text { ratio }\end{array}$ & $\begin{array}{l}\text { Total length } \\
\text { in } \mu\end{array}$ & $\begin{array}{c}\text { Relative } \\
\text { length }\end{array}$ & $\begin{array}{l}\text { Arm } \\
\text { ratio }\end{array}$ \\
\hline $\begin{array}{r}\text { I } \\
\text { II } \\
\text { III } \\
\text { IV } \\
\text { V } \\
\text { VI } \\
\text { VII } \\
\text { VIII } \\
\text { IX } \\
\text { X }\end{array}$ & $\begin{array}{l}73.21 \pm 2.09 \\
60.33 \pm 2.03 \\
43.46 \pm 1.34 \\
40.06 \pm 1.22 \\
38.82 \pm 1.38 \\
38.80 \pm 1.31 \\
34.65 \pm 1.27 \\
31.78 \pm 1.27 \\
29.46 \pm 1.18 \\
26.60 \pm 1.45\end{array}$ & $\begin{array}{r}100 \\
82 \\
59 \\
55 \\
53 \\
53 \\
47 \\
43 \\
40 \\
38\end{array}$ & \begin{tabular}{ll|}
$1: 1.22$ \\
$1: 1.21$ \\
$1: 1.17$ \\
$1: 1.43$ \\
$1: 1.02$ \\
$1: 4.50$ \\
$1: 1.33$ \\
$1: 1.11$ \\
$1: 1.05$ \\
$1: 1.14$
\end{tabular} & $\begin{array}{l}76.43 \pm 1.73 \\
54.91 \pm 1.32 \\
42.58 \pm 1.26 \\
38.57 \pm 1.80 \\
35.05 \pm 1.95 \\
34.46 \pm 1.09 \\
30.20 \pm 1.76 \\
27.31 \pm 1.40 \\
26.11 \pm 1.03 \\
22.82 \pm 1.74\end{array}$ & $\begin{array}{r}100 \\
72 \\
56 \\
50 \\
46 \\
45 \\
40 \\
36 \\
34 \\
30\end{array}$ & $\begin{array}{l}1: 1.13 \\
1: 1.39 \\
1: 1.59 \\
1: 1.24 \\
1: 1.14 \\
1: 3.99 \\
1: 1.09 \\
1: 1.13 \\
1: 1.13 \\
1: 1.18\end{array}$ & $\begin{array}{l}61.57 \pm 2.19 \\
45.87 \pm 1.64 \\
42.66 \pm 1.65 \\
38.04 \pm 1.62 \\
35.43 \pm 0.71 \\
35.28 \pm 1.24 \\
28.74 \pm 1.00 \\
26.33 \pm 1.26 \\
22.37 \pm 1.71 \\
21.47 \pm 1.61\end{array}$ & $\begin{array}{r}100 \\
75 \\
69 \\
62 \\
58 \\
57 \\
47 \\
43 \\
36 \\
35\end{array}$ & $\begin{array}{l}1: 1.08 \\
1: 1.26 \\
1: 1.22 \\
1: 1.14 \\
1: 1.21 \\
1: 4.75 \\
1: 1.23 \\
1: 1.24 \\
1: 1.29 \\
1: 1.10\end{array}$ \\
\hline
\end{tabular}

the centromere is followed by a small deeply stained region. In $S$. margaritiferum and $S$. aethiopicum, the pycnotic region on the short arm is followed by a single chromomere each whereas in Sheosagar this region on the short arm is followed by 3 chromomeres. Generally, the long arm is devoid of any chromomere except in Sheosagar where the pycnotic region on this arm is followed by a single chromomere.

Chromosome II: The pycnotic regions on both the arms are more or less of equal length in S. aethiopicum, Ramkel and Janera Joshia. However, in S. margaritiferum and Saoner, pycnotic region on the short arm is longer than that on the long arm though the reverse distribution is also found in the case of Sheosagar. While the pycnotic region on the short arm is followed by 2 chromomeres in $S$. margaritiferum, Ramkel and Sheosagar, there is only one chromomere on this arm in Janera Joshia. The remaining species do not possess any chromomeres on the short arm. Again, $S$. margaritiferum, S. aethiopicum and Sheosagar possess only a single chromomere each following the pycnotic region on the long arm while in the remaining taxa under study this arm is devoid of any distinct chromomeres.

Chromosome III: Pycnotic regions on both the arms are more or less equal in length in S. margaritiferum, S. aethiopicum and Ramkel. However, in Saoner, Sheosagar and Janera Joshia, the pycnotic region on the long arm is longer than that on the short arm. The pycnotic region on the short arm is followed by a single chromomere each in S. margaritiferum, S. aethiopicum and Sheosagar. The remaining species, however, 


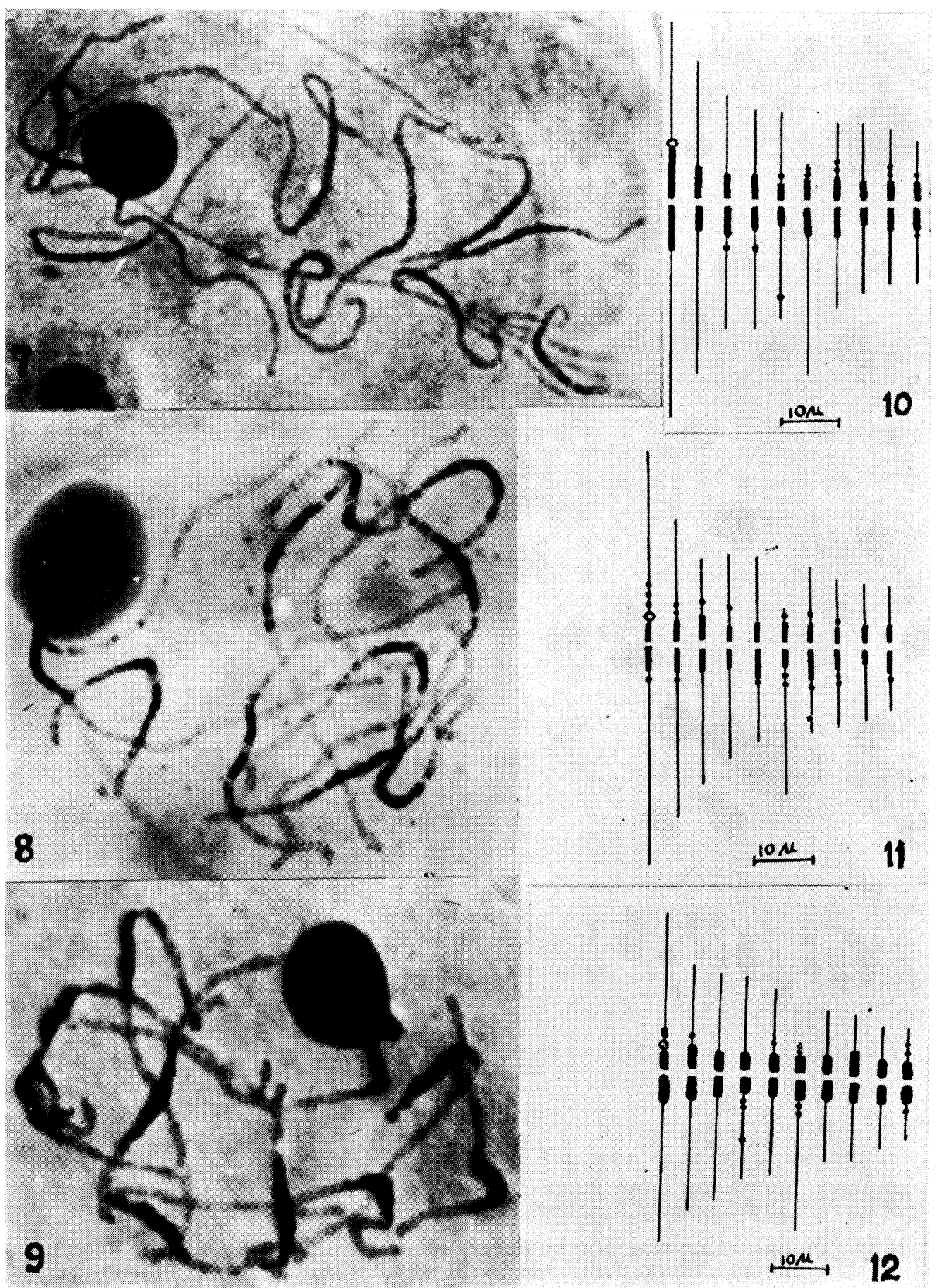

Figs. 7 to 9 . Ten pachytene bivalents of Saoner; Sheosagar and Janera Joshia respectively (X 1250; 1200 and 1560 respectively).

Figs. 10 to 12. The idiogram of the pachytene chromosomes of D-Saoner; E-Sheosagar and F.-Janera Joshia respectively. 


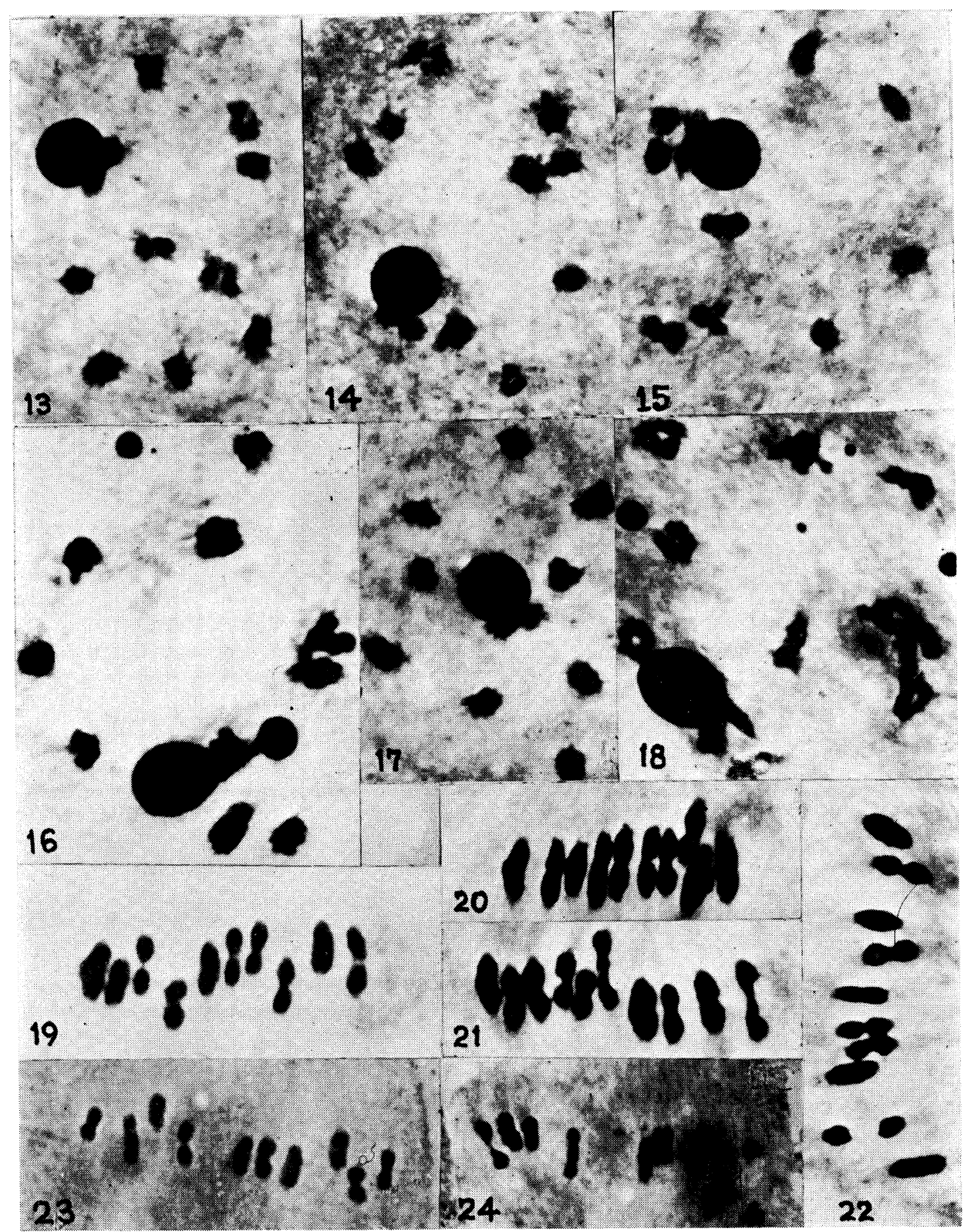

Figs. 13 to 18. Diakinesis showing ten bivalents in S. margaritiferum (X 1260); S. aethiopicum (X 1250); Ramkel (X 1560); Saoner (X 1685); Sheosagar (X 1500) and Janera Joshia (X 1625) respectively.

Figs. 19 to 24. Metaphase I showing ten bivalents in S. margaritiferum (X 2000); S. aethiopicum (X 1937); Ramkel (X 1875); Saoner (X 1625); Sheosagar (X 1625) and Janera Joshia (X 1875) respectively. 
Table 2. Showing chiasma frequency in the six Eu-Sorghums under study

\begin{tabular}{|c|c|c|c|c|c|c|c|}
\hline \multirow{2}{*}{$\begin{array}{c}\text { Species \& } \\
\text { varieties }\end{array}$} & \multirow{2}{*}{ Stage } & \multirow{2}{*}{$\begin{array}{l}\text { No. of } \\
\text { cells } \\
\text { analyzed }\end{array}$} & \multicolumn{3}{|c|}{ Bivalents with } & \multirow{2}{*}{$\begin{array}{l}\text { Total } \\
\text { No. of } \\
\text { xta }\end{array}$} & \multirow{2}{*}{$\begin{array}{c}\text { Average no. of } \\
\text { chiasmata per } \\
\text { cell }\end{array}$} \\
\hline & & & $2 \mathrm{xta}$ & $1 \mathrm{xma}$ & $\begin{array}{l}0 \\
\mathrm{xma}\end{array}$ & & \\
\hline S. margaratiferum & $\begin{array}{l}\text { Dia } \\
\text { MI }\end{array}$ & $\begin{array}{l}40 \\
40\end{array}$ & $\begin{array}{l}375 \\
247\end{array}$ & $\begin{array}{r}25 \\
153\end{array}$ & - & $\begin{array}{l}775 \\
647\end{array}$ & $\begin{array}{l}19.38 \pm 0.106 \\
16.18 \pm 0.138\end{array}$ \\
\hline S. aethiopicum & $\begin{array}{l}\text { Dia } \\
\text { MI }\end{array}$ & $\begin{array}{l}40 \\
40\end{array}$ & $\begin{array}{l}383 \\
230\end{array}$ & $\begin{array}{r}17 \\
170\end{array}$ & - & $\begin{array}{l}783 \\
630\end{array}$ & $\begin{array}{l}19.56 \pm 0.087 \\
15.75 \pm 0.171\end{array}$ \\
\hline Ramkel & $\begin{array}{l}\text { Dia } \\
\text { MI }\end{array}$ & $\begin{array}{l}40 \\
40\end{array}$ & $\begin{array}{l}385 \\
194\end{array}$ & $\begin{array}{r}15 \\
206\end{array}$ & - & $\begin{array}{l}785 \\
594\end{array}$ & $\begin{array}{l}19.63 \pm 0.078 \\
14.85 \pm 0.105\end{array}$ \\
\hline Saoner & $\begin{array}{l}\text { Dia } \\
\text { MI }\end{array}$ & $\begin{array}{l}40 \\
40\end{array}$ & $\begin{array}{l}378 \\
189\end{array}$ & $\begin{array}{r}22 \\
211\end{array}$ & - & $\begin{array}{l}778 \\
589\end{array}$ & $\begin{array}{l}19.45 \pm 0.080 \\
14.75 \pm 0.134\end{array}$ \\
\hline Sheosagar & $\begin{array}{l}\text { Dia } \\
\text { MI }\end{array}$ & $\begin{array}{l}40 \\
40\end{array}$ & $\begin{array}{l}376 \\
215\end{array}$ & $\begin{array}{r}20 \\
170\end{array}$ & $\begin{array}{r}4 \\
15\end{array}$ & $\begin{array}{l}772 \\
600\end{array}$ & $\begin{array}{l}19.30 \pm 0.125 \\
15.00 \pm 0.203\end{array}$ \\
\hline Janera Joshia & $\begin{array}{l}\text { Dia } \\
\text { MI }\end{array}$ & $\begin{array}{l}40 \\
40\end{array}$ & $\begin{array}{l}377 \\
151\end{array}$ & $\begin{array}{r}23 \\
249\end{array}$ & - & $\begin{array}{l}777 \\
551\end{array}$ & $\begin{array}{l}19.43 \pm 0.113 \\
13.78 \pm 0.121\end{array}$ \\
\hline
\end{tabular}

do not possess any chromomere on the short arm. Again, on the long arm, the pycnotic region is followed by a single chromomere only in the case of Saoner.

Chromosome IV: The pycnotic region on the long arm is longer than that on the short arm in S. aethiopicum, Ramkel, Saoner and Sheosagar. However, the reverse is the case in Janera Joshia. Further, in S. margaritiferum, the pycnotic region on both the arms are more or less euqal in length. The pycnotic region on the long arm is followed by a single chromomere each in S. aethiopicum and Saoner. However, a single prominent sub-terminal chromomere is also noted on this arm in Ramkel. In Janera Joshia, however, 2 chromomeres situated close to the pycnotic region and one distally situated chromomere are noted on this long arm. In the case of S. aethiopicum and Sheosagar, the short arm has a single chromomere each following the pycnotic region while the remaining taxa do not possess any chromomeres on this arm.

Chromosome $V$ : The pycnotic region on the long arm is slightly longer than that on the short arm in almost all the cases except in S. aethiopicum where converse is true and also in S. margaritiferum and Janera Joshia, where such regions are almost equal in length on both the arms. In S. margaritiferum, S. aethiopicum and Ramkel, both the arms are devoid of any distinct chromomeres. However, in Sheosagar the long arm has one chromomere following the pycnotic region. Further, on the same arm, there is a distantly situated chromomere in Saoner. A single chromomere is also noted on the short arm following the pycnotic region only in Saoner and Janera Joshia. Chromosome VI: It is the most asymmetrical chromosome of the complement. The pycnotic region is longer on the long arm as compared to that on the short arm in Ramkel and Saoner while the converse is, however, true in Sheosagar and Janera Joshia. In the case of $S$. margaritiferum and $S$. aethiopicum, the pycnotic regions on both the arms are almost equal in length. The deeply staining regions on both the arms are 
followed by 2 chromomeres each in S. margaritiferum, $S$. aethiopicum and Janera Joshia. However, the pycnotic region on the short arm is followed by 1, 2 and 3 chromomeres in Sheosagar, Saoner and Ramkel respectively. Further, the long arm in Ramkel and Shoesagar possesses one and two chromomeres respectively following the pycnotic region. Chromosome VII: The deeply staining regions on both the arms are of almost equal length in S. aethiopicum, Ramkel and Janera Joshia. However, the pycnotic region is longer on the long arm than that on the short arm in Saoner, Sheosagar and the converse is true in $S$. margaritiferum. Both the arms are devoid of any chromomeres in $S$. margaritiferum, Ramkel and Jenera Joshia. In the case of $S$. aethiopicum, the long arm bears a single sub-terminal chromomere and the same arm in Sheosagar possesses a single chromomere following the pycnotic region. The short arm possesses 1 and 2 chromomeres following the pycnotic region in Sheosagar and Saoner respectively.

Chromosome VIII: The pycnotic regions on both the arms are almost of equal length in S. margaritiferum, Ramkel and Saoner. However, the pycnotic region is longer on the long arm than that on the short arm in S. aethiopicum and Sheosagar whereas the converse is true in Janera Joshia. In the case of Saoner and Janera Joshia both the arms are devoid of any chromomeres. However, S. margaritiferum has one chromomere on each of the arms following the pycnotic regions. The long arm in S. aethiopicum and Sheosagar possesses 2 chromomeres each following the pycnotic region. In Ramkel, the short arm bears a terminal chromomere and sub-terminal knob. Again, in Sheosagar, the short arm has a single chromomere following the pycnotic region.

Chromosome IX: The pycnotic region is longer on the long arm than that on the short arm in all cases except in Sheosagar, where converse is true. In S. aethiopicum, Sheosagar and Janera Joshia both the arms are devoid of any distinct chromomeres. However, the pycnotic region on the short arm is followed by one and two chromomeres in S. margaritiferum and Saoner respectively. Again on the long arm a single distally located chromomere is noted following the pycnotic region only in Ramkel.

Chromosome $X$ : This is the shortest chromosome in the complement. The pycnotic region is longer on the long arm than that on the short arm in all the "species" except in Saoner where such regions are almost of equal length on both the arms. In the case of S. margaritiferum, S. aethiopicum and Sheosagar the pycnotic region on the long arm is followed by a single chromomere each, while such regions on the short arm end abruptly. However, in Saoner the pycnotic regions on both the arms are followed by a single chromomere. In Janera Joshia, the pycnotic region on the long arm is followed by a single chromomere, while on the short arm it is followed by 2 chromomeres. In Ramkel, a single sub-terminal chromomere can be differentiated only on the short arm.

2. Microsporogenesis :

Ten bivalents were usually present both at diakinesis and MI (Figs. 13 to 24). Normally one nucleolus was observed at diakinesis. However, presence of 2 to 4 nucleoli 
in Saoner and 2 to 10 Janera Joshia probably due to fragmentation were also occasionally noted at this stage (Figs. 16 and 18). At MI, a tendency for precocious separation of 1 to 2 bivalents was also occasionally noted in Saoner and Janera Joshia (Figs. 22 and 24). The data on the mean chiasma frequency per cell determined at these stages are presented in Table II. Anaphase I and later meiotic stages were also found to be regular resulting in high percentage of pollen stainability and good seed setting.

\section{DISCUSSION}

Since the classic work of McClintock (1929) in Zea mays, the potential importance of pachytene analysis and its wide application to cytogenetical and evolutionary problems has been well realized. Taking into consideration all the available information on the morphology of pachytene chromosomes in many crop plants, pachytene chromosomes may be broadly classified into two groups such as (a) those having undifferentiated chromosomes where the chromosomes take uniform stain throughout their length and exhibit only the size gradients like those found in S. intrans, Secale, Agapanthus, Sorghum purpureosericeum, and Hordeum and (b) those where the chromosomes are well differentiated into the achromatin and chromatin regions, chromomeres, knobs and centromeres, such as those reported in Zea mays, Lycopersicum, Plantago, and Solanum (see for review Sadasivaiah and Magoon, 1965). The Eu-Sorghums presented here belong to latter category of differentiated class. It may, however, be noted that this behaviour is not a characteristic feature of the entire genus since undifferentiated types of chromosomes have also been reported in certain species belonging to different sections.

On comparison of the six karyotypes presented in the present investigation, it can be seen that chromosome I, the longest chromosome in the complement, is always found associated with the nucleolus. This chromosome, does not show any marked length variation except in the cultivar Janera Joshia. The arm ratios however, do vary. The pycnotic region is generally distributed equally on both the arms or is slightly more on the long arm. The presence of 1 to 3 chromomeres on the short arm following the pycnotic region is usually observed in S. margaritiferum, S. aethiopicum and Sheosagar and except for the cultivar Sheosagar, long arm of the chromosome is generally devoid of well differentiated chromomeres. In cultivars, Ramkel, Saoner, and Janera Joshia, chromomeres could not be detected on both the arms. The consistency in length and other morphological features found in the five Eu-Sorghums shows that this chromosome has not undergone very marked variation during the course of evolution. The length of the second chromosome in these six Eu-Sorghums also does not differ much and ranges between $60.33 \mu$ to $54.91 \mu$ except in Janera Joshia where it is $45.87 \mu$. Comparatively, it is the second asymetrical chromosome in the complement except in Ramkel and Saoner where its arm ratio tends towards symmetry. Except for Saoner, in all the other five Eu-Sorghums, 1 to 2 chromomeres are seen on either or both the arms of 
this chromosome. Generally, the short arm possesses two chromomeres. Pycnotic region is almost equal in length on both the arms but in S. margaritiferum and Saoner, the long arm possesses shorter pycnotic region as compared to that on the short arm.

The length of third chromosome ranges between $42.58 \mu$ to $52.07 \mu$ and no variation is exhibited even by Janera Joshia in respect of length of this chromosome. Comparatively, the centromere of this chromosome is median. The striking feature that is exhibited by this member of the complement is the sparsely distinguishable chromomeres on its arms. The pycnotic region is almost equal on its arms except in Saoner where it is longer on the long arm than that on the short arm. The consistency in morphological features of this chromosome that is observed in such geographically distant forms indicates that the cytologically detectable evolutionary changes do not appear to have affected this chromosome to a considerable extent.

The fourth and fifth chromosomes are almost equal in length, arm ratio, chromomeric pattern and distribution of pycnotic regions on both the arms. The length of the fourth chromosome ranges between $38.08 \mu$ to $43.96 \mu$ whereas that of fifth ranges between $35.05 \mu$ to $40.55 \mu$. Pycnotic region is invariably longer on the long arm than that on the short arm. However, a slight variation is noticed in its distribution. Both the arms bear either a single chromomere each or they are devoid of it. However, the fourth chromosome of Janera Joshia is characterized by three chromomeres on its long arm whereas on its short arm chromomeres are not differentiated.

Chromosome VI is identified by virtue of its most asymmetrical nature. The pycnotic region on its arm is almost equal or slightly longer on the long arm in some cases. Invariably, this region is followed by 1 to 3 chromomeres on both the arms.

Chromosomes VII, VIII, IX and X differ slightly in the position of centromere from each other in these Eu-Sorghums but show remarkable differences in length from the chromosomes I to VI described above. This group also shows much more variability in their chromomeric pattern and distribution of pycnotic regions.

In general, it is, therefore, observed that the wild species and fodder type cultivars are characterized by having more number of chromomeres on the chromosomes while the grained varieties have comparatively lower number. This agrees with the findings of Mangelsdorf and Cameron (1942) who in their detailed study of the karyotypes of races in maize and its relatives found that wild relatives or primitive types have more number of knobs as against low number in cultivated ones. Further, it would be evident from the results presented here that the length measurements between the longest chromosome and the shortest chromosome in the complement in these six EuSorghums show significant difference. The proportion of the longest chromosome to the shortest in each of the Eu-Sorghum is little more than $2: 1$. In each karyotype there is at least one asymmetrical chromosome and hence following the classification suggested by Stebbins (1958) all the six karyotypes studied fall under ' $2 \mathrm{~b}$ ' type of asymmetry class. The excessive development of pycnotic material on the chromosomes 
in Janere Joshia has been noted in the present study. The possibility of such an occurrence due to the chemical effect of the fixative is ruled out since all of these EuSorghums were subjected to the identical treatment of fixation, staining and further processing. However, if Darlington's (1937) suggestion that the chromatin behaviour is governed by the genotype is accepted, then it could be possible that the gene or genes which are responsible for the synthesis of heterochromatin in the chromosomes are more active in Janera Joshia than in the other five Eu-Sorghums.

On the whole it may thus be seen from the facts presented above that the comparative study of the pachytene chromosomes in the Eu-Sorghums under consideration, brings out a good deal of similarity in general morphology and almost similar basic set pattern in organization. However, some differences are also noted between them. It may, however, be noted that the marked karyomorphological differences in the somatic karyotypes of the different Sorghums species noted by Sharma and Bhattacharjee (1957) could not be confirmed even in the study of pachytene chromosomes in these Eu-Sorghums. This, thus suggests that the data from the somatic chromosomes are to be interpreted with care in this genus since one is dealing with lengths of relatively shorter magnitude subject to vagaries of fixation and further processing (see Magoon et al. 1964).

On the basis of comparative chromosome morphology and karyotypes of these EuSorghums, the ten chromosomes of haploid complement in them can be broadly classified into a group of five longer chromosomes (Chromosome I to V) and a group of five shorter chromosomes (Chromosome VI to X). It is now well accepted that in the genus Sorghum, the basic chromosome number is 5 which is considered to be derived from a primitive higher number. The chromosome demunition is of common occurrence in the highly evolved forms and a series of basic chromosome numbers are found in the species belonging to the same genus. Such a descending order in basic chromosome number has been compiled by Stebbins (1958) where out of the 31 genera, 25 showed such a pattern. In the genus Sorghum also the super-numerary chromosomes have been recorded (Magoon et al. 1961 a) and species like S. purpureo-sericeum and others are reported to have $(2 n)$ number ranging from 10 to 14 . It is likely that the present basic chromosome number 5 of the genus Sorghum have been evolved due to the gross structural changes like translocation and elimination of accentric fragments from the basic chromosome number 7 . The presence of asymmetrical chromosome VI in EuSorghums also supports this view since all other chromosomes are either metacentric or sub-metacentric and occurrence of such asymmetry in this particular chromosome can be assigned to the translocation of the portion of its short arm to some other chromosomes or the elimination from the chromatin material. Further, if the hypothesis of allo-polyploid origin of Sorghum and 5 being the basic chromosome number is considered (see Magoon and Shambulingappa 1961 and 1963), then the observations recorded in the present study also suggest that the present 20-chromosomed Eu-Sorghums might have been derived as a result of the cross between two putative species one 
donating a set of five longer chromosomes and another, a set of five shorter chromosomes followed by doubling of chromosome number in the hybrid. Nevertheless, the present type of karyotype might have been established through further evolutionary and selective mechanisms. The later alternations in chromosomes which gave rise to the different 'species' and races may be mostly of the nature of 'cryptic' or small scale structural differences.

Huskins and Smith (1934 vide Magoon et al. 1961b) reported quadrivalent formation in the diploid Sorghum species at MI. However, only bivalent formation have been recorded in the Eu-Sorghums under study. The later meiotic stages were also found to be regular. Usually, no significant difference in the mean chiasma frequency is noticed at diakinesis and MI. However, a significant reduction in Janera Joshia and significantly higher values for $S$. margaritiferum (see Table 2 ) point towards the positive correlation between chromosome size and chiasmata formation as recorded by Henderson (1963) though alternatively genotypic control on chiasma formation cannot be ruled out for such an occurrence.

\section{SUMMARY}

The detailed morphology of the pachytene chromosomes and microsporogenesis have been studied in the six Eu-Sorghums. The pachytene chromosomes are depicted on the basis of total length, relative length, arm ratio, amount and distribution of heterochromatin and number and position of chromomeres. The characteristics of each of the ten pachytene bivalents in the haploid complement are described in detail bringing out similarities and differences amongst them. Based on the idiograms of the pachytene chromosomes, the possible role of chromosomes in speciation and the relationship amongst these Eu-Sorghums are discussed. Two basic archetypes in the 20-chromosomed taxa have been suggested-one with five long chromosomes and the other with five short chromosomes. It is proposed that the present day cultivated forms of Eu-Sorghums are allopolyploids of crosses between two such forms.

\section{LITERATURE CITED}

Barton, D. W., 1950 Pachytene morphology of the tomato chromosome complement. Am. J. Botan. 37: $639-43$.

Darlington, C. D., 1937 Recent advances in cytology. J. and A. Churchill Ltd., London.

Henderson, S. A., 1963 Chiasma distribution at diplotene in a locust. J. Heredity 18: 173-190.

Magoon, M. L., P. L. Manchanda, and M. S. Ramanna, 1964 Cytological and morphological studies in the genus Sorghum. Cytologia 29: 42-60.

Magoon, M. L., M. S. Ramanna, and K. G. Shambulingappa, 1961a Desynapsis and spontaneous chromosome breakage in Sorghum purpureosericeum. Indian J. Genet. 21: 87-97.

Magoon, M. L., K. G. Shambulingappa, and M.S. Ramanna, 1961b Chromosome morphology and meiosis in some Eu-Sorghums. Cytologia 26: 236-252. 
Magoon, M. L., and K. G. Shambulingappa, 1961 Karyomorphology of Sorghum propinquum and its bearing on the origin of 40-chromosomed Sorghums. Chromosoma 12: 460-65.

Magoon, M. L., and K. G. Shambulingappa, 1963 Cytomorphological studies of some species and hybrids in the Eu-Sorghums. Chromosoma (Berl.) 14: 572-588.

Mangelsdorf, P.C. and J. W. Cameron, 1942 Western Guatemala, a secondary centre of origin of cultivated maize varieties. Bot. Mus. Leal. Harv., 10: 217-56.

McClintock, B., 1929 Chromosome morphology in Zea mays. Science 69: 629.

Randolph, L. F., 1948 Inherited differences in pachytene configurations in maize. Genetics, 33: 121.

Rees, H., 1961 Genotypic control of chromosome form and behaviour. Botan. Rev. 27: 288-318.

Sadasivaiah, R. S. and M. L. Magoon, 1965 Morphology of the pachytene chromosomes and microsporogenesis in some Eu-Sorghums. La cellule (in press).

Sharma, A. K., ond D. Bhattacharjee, 1957 Chromosome studies in Sorghum I. Cytologia 22: 287-311.

Stebbins, G. L., 1958 The inviability, weakness and sterility of interspecific hybrids. Advan. Genet 9: $147-215$.

Swaminathan, M. S., M. L. Magoon, and K. L. Mehra, 1954 A simple propionocarmine PMC smear method for plants with small chromosomes. Indian J. Genet. 14: 87-88.

Wellwood, A. A. and L. F. Randolph, 1957 Inheritance of differences in pachytene chromosome configuration in maize. Amer. J. Bot. 44: 129-35. 